\title{
Comparing Faculty Information Seeking in Teaching and Research: Implications for the Design of Digital Libraries
}

\author{
Christine L. Borgman and Laura J. Smart* \\ Department of Information Studies, Graduate School of Education \& Information Studies, University of California \\ Los Angeles, Los Angeles, CA 90095-1520. E-mail: borgman@gseis.ucla.edu
}

Kelli A. Millwood

Department of Education, Graduate School of Education \& Information Studies, University of California

Los Angeles, Los Angeles, CA 90095-1520

Jason R. Finley

Department of Psychology, College of Letters and Sciences and Department of Information Studies, Graduate

School of Education \& Information Studies, University of California Los Angeles, Los Angeles, CA 90095-1520

Leslie Champeny, Anne J. Gilliland, and Gregory H. Leazer

Department of Information Studies, Graduate School of Education \& Information Studies, University of California Los Angeles, Los Angeles, CA 90095-1520

\begin{abstract}
ADEPT is a 5-year project whose goals are to develop, deploy, and evaluate inquiry learning capabilities for the Alexandria Digital Library, an extant digital library of primary sources in geography. We interviewed nine geography faculty members who teach undergraduate courses about their information seeking for research and teaching and their use of information resources in teaching. These data were supplemented by interviews with four faculty members from another ADEPT study about the nature of knowledge in geography. Among our key findings are that geography faculty are more likely to encounter useful teaching resources while seeking research resources than vice versa, although the influence goes in both directions. Their greatest information needs are for research data, maps, and images. They desire better searching by concept or theme, in addition to searching by location and place name. They make extensive use of their own research resources in their teaching. Among the implications for functionality and architecture of geographic digital libraries for educational use are that personal digital libraries are essential, because individual faculty members have personalized approaches to selecting, collecting, and organizing teaching resources. Digital library services for research
\end{abstract}

*Current address: Library, Cal Poly Pomona, Pomona, CA.

Received August 15, 2003; revised May 4, 2004; accepted May 4, 2004

(C) 2005 Wiley Periodicals, Inc. • Published online 9 February 2005 in Wiley InterScience (www.interscience.wiley.com). DOI: 10.1002/asi.20154 and teaching should include the ability to import content from common office software and to store content in standard formats that can be exported to other applications. Digital library services can facilitate sharing among faculty but cannot overcome barriers such as intellectual property rights, access to proprietary research data, or the desire of individuals to maintain control over their own resources. Faculty use of primary and secondary resources needs to be better understood if we are to design successful digital libraries for research and teaching.

\section{Introduction}

Digital libraries can support information seeking, creation, and use for a wide variety of applications, one of the most promising of which is education. They can facilitate inquiry learning, which is a method of involving students in scientific or other scholarly practices so that they gain a deeper epistemological understanding of the discipline (Sandoval, 1999; Sandoval \& Reiser, 2003). Scientists, and other scholars, use the content in digital libraries in support of their research. Students, by using the same content, can learn scientific and scholarly practices in ways more consonant with that of scholarly communities than through learning via textbooks.

In an effort to explore the value of digital libraries (DL) for inquiry learning in geography, we are developing a geospatial DL to support undergraduate education. The 
Alexandria Digital Earth Prototype Project (ADEPT) is a 5-year (1999-2004) effort based at the University of California, Santa Barbara (UCSB), with multiple partners. ${ }^{1}$ The education and evaluation component of the ADEPT project addresses two general research questions: how to design a useful digital library for undergraduate education in geography, and how to design a digital library that university faculty will choose to deploy. These are complementary research questions that rarely are pursued together. It is possible to design an effective and efficient system that is not adopted by the intended users. Conversely, technologies that are adopted may be suboptimal in design, but succeed because they provide sufficient value to their audience (Rogers, 1995). Earlier research by the ADEPT Education and Evaluation Team has explored geographic education, digital library design, and the practices and goals of faculty, teaching assistants, and students (Borgman et al., 2000; Borgman, Leazer, Gilliland-Swetland, \& Gazan, 2001; Borgman et al., 2004; Champeny et al., 2004; Gazan et al., 2003; Gilliland-Swetland \& Leazer, 2001; Leazer, GillilandSwetland, Borgman, \& Mayer, 2000; Mayer, Mautone, \& Prothero, 2002; Mayer, Smith, Borgman, \& Smart, 2002). Research on the conceptual and technical development of ADEPT has been reported by the implementation and knowledge teams (Borgman, 2004; Hill \& Freeston, 2003; Hill \& Janee, 2004; Hill, Janee, Dolin, Frew, \& Larsgaard, 1999; Janee \& Frew, 2002; Janee, Frew, \& Hill, 2004).

Our results indicate that faculty teaching styles vary widely, even in the same course (Borgman et al., 2000). Individual instructors of the same introductory course on physical geography chose different textbooks, emphasized different sets of geographic concepts, and employed different instructional styles such as their use of formal lectures, chalkboards, overhead projectors, maps, physical objects (e.g., rocks), course Web sites, and methods of evaluating students. We recognized early on that building collections and tools, which would be of value to such a diverse audience was a key challenge.

ADEPT is intended to be a set of tools and services that extended the functionality of the Alexandria Digital Library (ADL), which is a georeferenced digital library (http:// alexandria.ucsb.edu/adl/about_adl.html). ADL and ADEPT support the two fundamental types of georeferencing: place names and geospatial coordinates (primarily latitude and longitude). ADEPT includes a sophisticated gazetteer that links place names and locations (Hill \& Janee, 2004). However, as is typical of geographic information systems, ADL is not indexed by concepts, such as geographic features, agriculture, or population movements. Our studies of geography faculty indicate that searching by geographic event or process, such as "find good examples of adiabatic processes,"

${ }^{1}$ Development and support of the ADEPT system will continue via the DialogPlus Project at UCSB, Michael Freeston, Principal Investigator. Research on education and evaluation aspects of ADEPT will continue at UCLA to August, 2005, via a no-cost time extension to the ADEPT subcontract, Christine L. Borgman, Principal Investigator. is important for teaching purposes (Borgman et al., 2000a). These findings have led us to extend the scope of our research to assess what kinds of resources are needed for geography instruction (whether or not currently in the ADL) and what searching and manipulation capabilities are required.

The research reported here explores the informationseeking behaviors of geography faculty in support of teaching and research, with the specific goal of applying the results to the design of ADEPT. We recruited nine geographers from an array of specialties in physical and human geography, and asked them questions about how they seek information for teaching and research, and about how they use information resources in their teaching. These data are supplemented by interviews with four physical geographers conducted earlier in the project (1999-2000) about the nature of knowledge in geography. We do not claim broad generalizations from these small samples. Rather, we suggest implications for the design of DLs and identify questions for further research.

\section{Background and Literature Review}

The research reported here draws upon studies in information seeking, social studies of science, geography education, evaluation methods, and higher education. Although we have attempted to provide a succinct review of relevant areas of research, the discussion remains lengthy due to the number of variables involved.

\section{Digital Libraries}

Digital libraries are an emerging concept, despite a decade of research and development (Borgman, 1999; Borgman, 2000a). Our work builds upon the definition established in Borgman, Bates, Cloonan, Efthimiadis, Gilliland-Swetland, Kafai, et al. (1996):

1. Digital libraries are a set of electronic resources and associated technical capabilities for creating, searching, and using information. In this sense they are an extension and enhancement of information storage and retrieval systems that manipulate digital data in any medium (text, images, sounds; static or dynamic images) and exist in distributed networks. The content of digital libraries includes data, metadata that describe various aspects of the data (e.g., representation, creator, owner, reproduction rights), and metadata that consist of links or relationships to other data or metadata, whether internal or external to the digital library.

2. Digital libraries are constructed-collected and organized — by [and for] a community of users, and their functional capabilities support the information needs and uses of that community. They are a component of communities in which individuals and groups interact with each other, using data, information, and knowledge resources and systems. In this sense they are an extension, enhancement, and integration of a variety of information institutions as physical places where resources are selected, collected, organized, preserved, and accessed in 
support of a user community. These information institutions include, among others, libraries, museums, archives, and schools, but digital libraries also extend and serve other community settings, including classrooms, offices, laboratories, homes, and public spaces.

\section{ADEPT Architecture}

The current version of ADEPT has a rich set of tools and services to support course preparation and presentation (Champeny et al., 2004; Smith et al., 2003). It gives instructors the ability to create, search, and display a variety of learning materials, including geographic information objects (e.g., images, data sets, maps, animations), knowledge bases of course concepts and concept maps of the relationships among concepts, and presentation materials (e.g., lectures, lab exercises, self-guided presentations). (See Figures 1-3.) Course materials can be presented in multi-screen, multimedia formats in the classroom, laboratory, or on the Web. Resources assembled for the course are held in the instructor's "personal digital library" (PDL) within ADEPT. This architecture enables the instructor to share some or all of a PDL with other ADEPT users. The assembled resources are available to students on the course Web site. The first full-course deployment of this version of ADEPT took place in an introductory physical geography course in Fall term, 2002, and Spring term, 2003, taught by the same instructor.

The personal digital library architecture will allow collections and services to be tailored to individual practices without compromising the organization of the larger database. Further, by giving users the option of sharing some or all of their PDL with others, they can incorporate their own research data and proprietary sources without risk of releasing materials they do not wish to share openly (Borgman, 2000b). The appropriate architecture for ADEPT has been the subject of vigorous debate within the design team. Among the issues addressed were whether users should be supported in creating their own ad hoc collections, or whether formal collection development (in the traditional library sense) should be presumed (Hill et al., 1999). The design now supports PDLs.

\section{Education and Evaluation Research on the Alexandria Digital Earth Prototype (ADEPT)}

Despite the calls for more evaluation of digital libraries (Borgman, 2002; Borgman \& Larsen, 2003; Larsen \& Wactlar, 2004; Manduca, McMartin, \& Mogk, 2001; Marchionini \& Crane, 1994; National Science Foundation, 1999; Smith et al., 2003), few digital library projects are as actively engaged in evaluation as ADEPT. The ADEPT Education and Evaluation (E\&E) Team consists of faculty and student researchers at UCLA and UCSB with expertise in information studies, education, and psychology. Our role is to assist in systems design via formative, iterative, and summative evaluation. Activities to date include observing undergraduate courses in geography, interviewing faculty and students, gathering teaching materials used in geography courses, analyzing the instructional content of geography courses, identifying usability criteria and functionality, and conducting usability evaluations of prototypes. While most of our efforts have focused on physical geography, as that is the topic for which we have the richest collections in the ADL and it is the primary research area of the geographers who are members of the ADEPT design team, we also are studying human geography courses, instructors, and students.

The ADEPT alpha-prototype, constructed in PowerPoint with text, images, movies, and Web links, was deployed in the 1999-2000 academic year for selected lectures at both campuses. We interviewed faculty and students before and after the introduction of the alpha prototype and assessed the usability of the software. Results from these studies were used to write use case scenarios and enhanced software specifications for second-generation prototypes (Ancona, Freeston, Smith, \& Fabrikant, 2002; Coleman, Smith, Buchel, \& Mayer, 2001; Gazan et al., 2003). Substantial design changes resulted from these iterative evaluations, such as creating a three-screen display rather than a single-screen display for teaching, building separate modules for creating lectures, concept maps, and examples, and constructing personal digital libraries that could import content from instructors' collections.

In observing instructors in introductory courses, we found that they rarely cited specific sources of primary scientific evidence and spent little time relating scientific method to the development of geographic knowledge during lectures. However, these instructors indicated their desire to teach with the primary data and images that ADEPT could provide (Borgman et al., 2001). To facilitate the incorporation of primary resources in teaching, we need a better understanding of faculty's instructional preparation practices (i.e., selecting, gathering, organizing, and presenting materials).

Two key questions drive the next phase of our research: (a) how will ADEPT work in physical geography courses taught by other instructors, and (b) how will it work in courses in other subjects that employ geospatial content. We are deploying ADEPT in multiple classrooms in 2003-2004 to address these issues. The research reported in this article informs those implementations.

\section{Information Seeking and Use in Geography}

Geography is a particularly promising area of study for digital libraries because of the wealth of geospatial resources available and because of the difficulty of using many of those resources. Seeking, using, and creating geospatial resources such as maps, photos of the earth's surface and climate, and remote sensing data require geospatial reasoning ability. Geospatial reasoning is perhaps the most difficult aspect of learning geography, due to its cognitive complexity (Mark, 1997). This form of reasoning involves the relationship between space and time, comprehension of twodimensional representations of three-dimension space (or four-dimensional representation when time is a variable), 


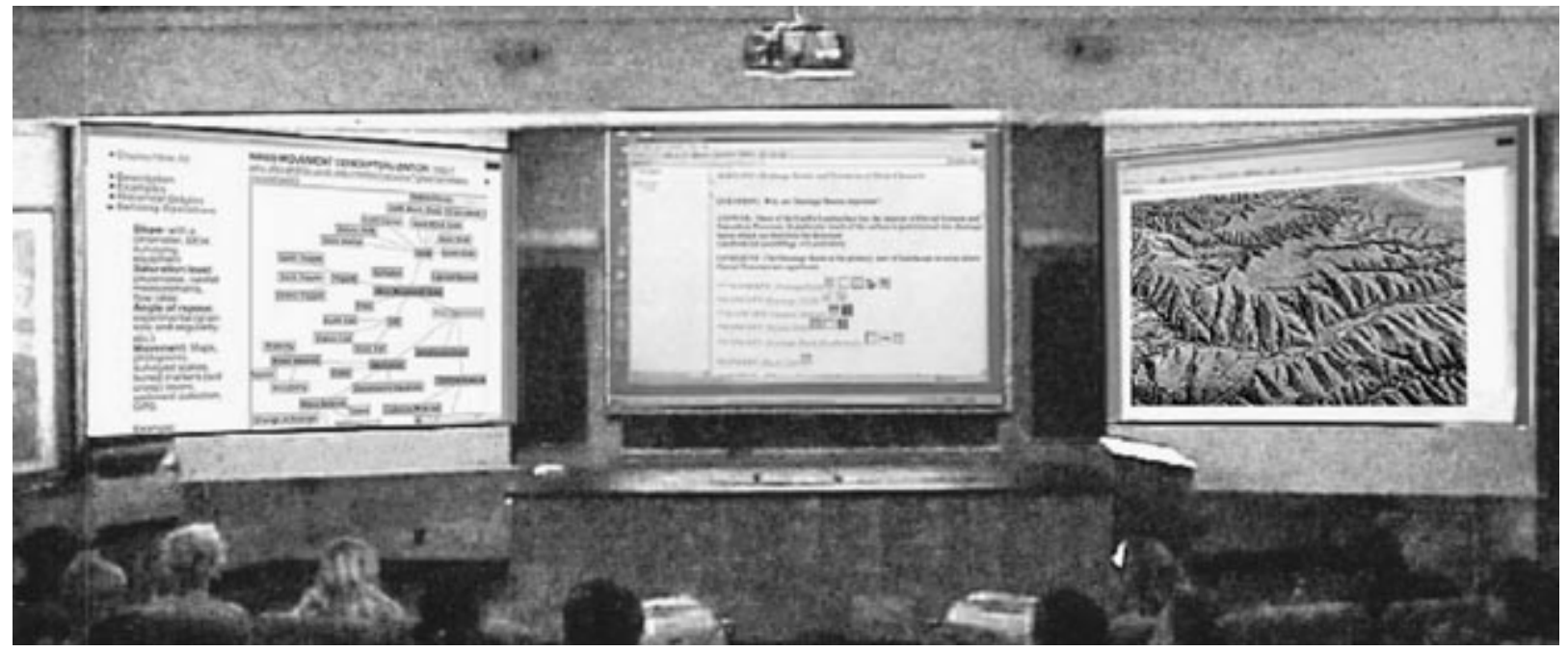

FIG. 1. ADEPT classroom presentation. From the left, the Knowledge window displays concepts and interrelationships between them. The central Lecture window displays the presentation materials, such as lecture, laboratory, or self-guided presentation. The Collection window on the right displays digital library items, such as images, maps, texts, and animations that illustrate the concept or interrelationships between concepts. From "The ADEPT conceptbased digital learning environment," by T.R. Smith, D. Ancona, O. Buchel, M. Freeston, W. Heller, R. Nottrott, et al. In T. Koch and I.T. Solvberg (Eds.), Research and Advanced Technology for Digital Libraries, 7th European Conference (ECDL 2003), p. 303. Copyright 2003 by Springer Publishing. Reprinted with permission of the author.

SUBTOPIC: Drainage Basins and Networks of River Channels

QUESTION: Why are Drainage Basins important?

ANSWER: Most of the Earth's Landsurface has the imprint of Fluvial Erosion and Deposition Processes. In particular much of the surface is partititioned into drainage basins which are therefore the dominant Landform (or assemblage of Landforms)

COMMENT: The Drainage Basin is the primary unit of Landscape in areas where Fluvial Processes are significant.

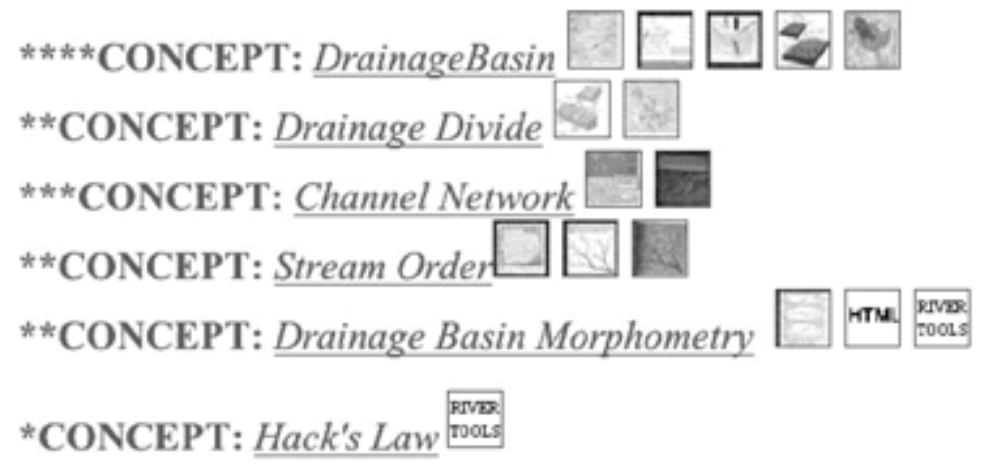

QUESTION: What are the most fundamental processes underlying the emergence of Stream Channels, Networks of Channels, and Drainage Basins?

FIG. 2. ADEPT Lecture window. From "The ADEPT concept-based digital learning environment," by T.R. Smith, D. Ancona, O. Buchel, M. Freeston, W. Heller, R. Nottrott, et al. In T. Koch and I.T. Solvberg (Eds.), Research and Advanced Technology for Digital Libraries, 7th European Conference (ECDL 2003), p. 308. Copyright 2003 by Springer Publishing. Adapted with permission of the author. 


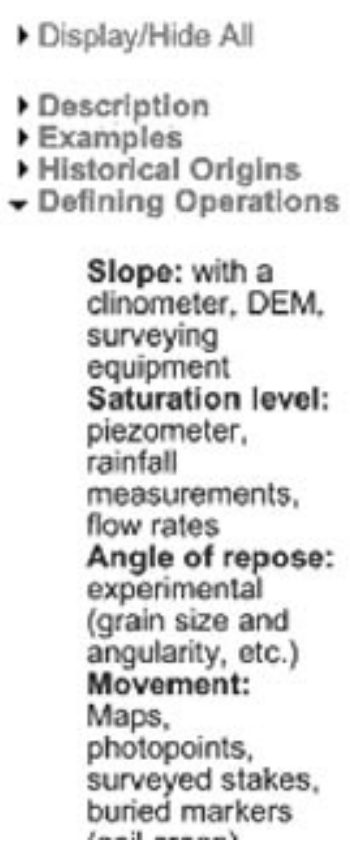

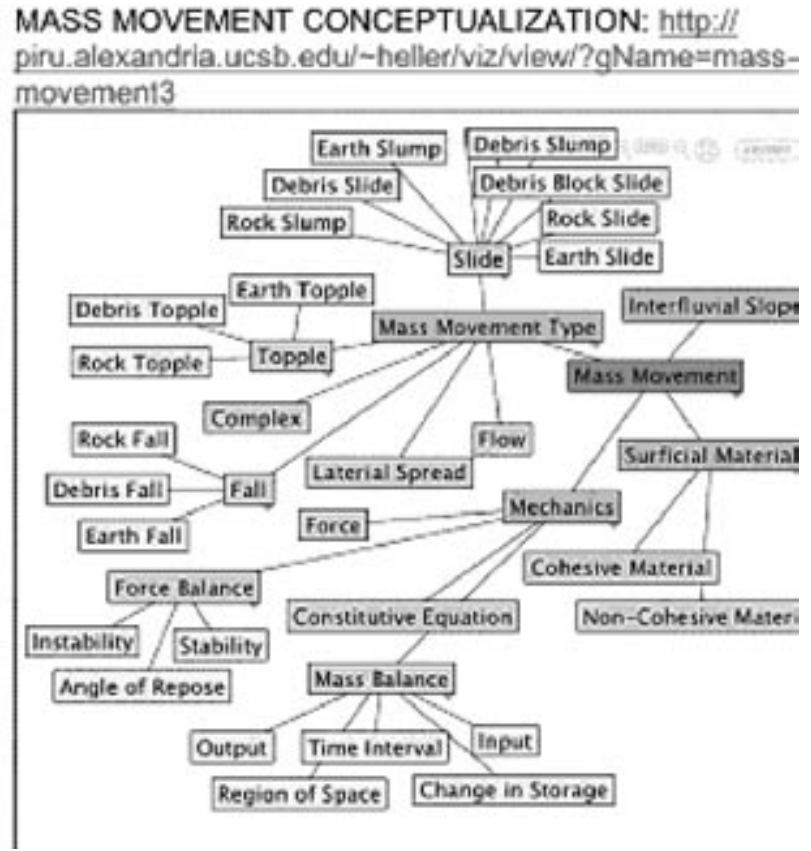

FIG. 3. Visual presentation of the Concept Space-the Concept of Mass Movement from the Physical Geography course. From "The ADEPT concept-based digital learning environment," by T.R. Smith, D. Ancona, O. Buchel, M. Freeston, W. Heller, R. Nottrott, et al. In T. Koch and I.T. Solvberg (Eds.), Research and Advanced Technology for Digital Libraries, 7th European Conference (ECDL 2003), p. 309. Copyright 2003 by Springer Publishing. Reprinted with permission of the author.

and often requires qualitative reasoning from incomplete data (Egenhofer \& Mark, 1995; Mark, 1997; Monmonier, 1993).

These complex relationships and representations are difficult to present in simple ways. Geographic information systems rely on formal, mathematical models to represent maps, images, and other geospatial data. Users of these systems must learn the formal representations to search and manipulate geospatial content. Instruction in the use of GIS usually consists of full academic courses at the upper division undergraduate level or at the graduate level, and is aimed at students specializing in geospatial topics. The learning requirements of GIS have been a barrier to making geospatial data accessible for introductory courses and for inquiry learning approaches to instruction. To make GIS usable with minimal instruction, these systems must support less formal, common-sense geographic reasoning, which is known as "naïve geography" (Egenhofer \& Mark, 1995; Larson, 1995). Searching for geographically located images is a key area for the design of ADEPT (Hill \& Freeston, 2003; Janee, Frew, \& Hill, 2004).

Much of introductory instruction in geography is devoted to learning geographic reasoning. The instructors we have observed spend substantial portions of classroom time displaying maps and images and explaining how to interpret them. Teaching assistants in laboratory sections also spend much time explaining representation concepts such as isolines, topography, and mercator projections. These representations are the subject of laboratory exercises and examina- tions. Geography textbooks are laden with maps, images, and diagrams. Many introductory texts now include CD-ROMs that contain additional maps, images, and movies of dynamic processes.

The challenges of geographic reasoning also are apparent in bibliographic control of maps and other geospatial data (Larsgaard, 1998; Monmonier, 1993). Finding maps can require several layers of search through guides to maps and atlases, and then through the maps and atlases themselves. Maps often are cataloged only as collections, without entries for individual maps. Many useful maps are uncataloged because they appear in books and articles. Once located, browsing maps that lie flat in 4' drawers is much more difficult than browsing books on a shelf. Even with a map in hand, external sources may be required to determine its accuracy and political factors that influenced its design (Monmonier, 1993). Thus, it is essential for the design of ADEPT that we understand more about how geography instructors search for maps and images and how they use those resources in teaching.

\section{Information Seeking by University Faculty}

Research on information needs and information-seeking behavior of academics extends back to the late 1950s (Hurych, 1986), beginning with simple descriptive studies and evolving into discipline-specific investigations (Hart, 1998). Excellent reviews include Case (2002), Dervin and Nilan (1986), Meadows (1998), Westbrook (1997), and 
Pettigrew, Fidel, and Bruce (2001). However, this body of research scarcely considers the multiple work roles of academics or their use of digital geospatial information. Studies typically characterize users by singular roles such as novice, expert, student, or faculty member within a specific discipline. Lagoze (1997) is among the few to note that one person may take on multiple roles within a single digital library interaction.

More holistic research will be needed to capture the cognitive, social, and organizational aspects of complex information-related behavior (Pettigrew et al., 2001). Leckie, Pettigrew, and Sylvain (1996) surveyed the literature on information seeking of engineers, lawyers, and healthcare professionals to determine commonalities across models. Their composite model includes a feedback loop that is initiated before another iteration of information seeking commences. While the feedback loop idea is common to other stage theories of information seeking (e.g., Bates, 1989; Kuhlthau, 1988, 1991), what is distinctive about the Leckie, Pettigrew, and Sylvain study is that "an outcome from one task associated with a particular role . . may quite unexpectedly benefit the professional in another role" (p. 187). Research on social networks also suggests that people share information with other people selectively, often with the expectation of reciprocity at some future time (Monge \& Contractor, 2003). Thus, information and work roles interact in a variety of complex ways.

\section{Information Seeking in Support of Teaching and Research}

Our concern in this study is the relationship between information seeking of academics in support of their teaching and in support of their research, which is a particularly under-studied topic. The only study we identified that compared information seeking in these two roles is that of Hart (1998), and his findings are not generalizable due to his sampling methods.

The dearth of research in this area is particularly notable given the long history in higher education of studying the relationship between the research and teaching roles of faculty (Astin 1993; Astin \& Chang 1995; Clark, 1997; Dill, 1999; Gottlieb \& Keith, 1997; Jenkins, 2000; Serow, 2000). Much of this body of work consists of statistical correlations between measures of research productivity and of teaching effectiveness. The correlations are generally high, and the strong relationship is presumed in academic lore and embodied in the evaluation criteria for faculty at research universities. Yet the correlations may be suspect due to measurement problems, to the halo effect of good research on perceptions of teaching, and to variations in the resources of universities (Astin, 1993; Astin \& Chang 1995; Jenkins, 2000). In a comprehensive study, Astin (1993) found that students were less satisfied and learned less well from faculty who were more research oriented. Of particular interest is Jenkins' (2000) analysis of higher education research in the field of geography. He concludes that research and teaching are all too often separate and competing activities. Fac- ulty members' research should be integrated into their teaching in ways that can stimulate students to more active learning, to understanding the nature of research, and to viewing geography as a research-based discipline.

\section{Inquiry Learning}

Inquiry learning approaches that bring scientific or scholarly experiences to the classroom are central to integrating teaching and research at the undergraduate level (Jenkins, 2000; Reinventing Undergraduate Education, 1998, 2001). Providing context for research questions is a central goal of inquiry learning. In education research, context can be framed in terms of the fidelity between "real" scientific practice and the tools and practices of classrooms. At one pole of educational researchers are those who advocate maintaining a high degree of fidelity between what students do and what scientists do by having the students get involved in live, ongoing scientific studies often "at the elbows" of real scientists doing their own research (Hay \& Barab, 2001). At the other pole are approaches that create self-contained learning communities within the classroom. They model the process of scientific investigation but do not work directly with scientists (Reiser et al., 2001). The design of tools for accessing, analyzing and presenting scientific data will vary by the approach chosen. Inquiry learning addresses epistemology directly by assisting students to "think like scientists" rather than to learn "about science" from textbooks and small, often artificial, experiments (Sandoval, 1999; Sandoval \& Reiser, 2003). Thus, the match between how science is done and how scientific data are represented in digital libraries may be as critical for science learners as for scientists (Borgman, 2004).

Fidelity between the practice of science and the learning of science will require ways of describing data so that they are useful and usable for both purposes. When designing digital libraries for use by faculty, teaching assistants, and undergraduate students, differences in expert and novice behavior become apparent. Faculty, who hold $\mathrm{PhDs}$ in their field of study, bring a much deeper knowledge of the scholarly process and domain to their use of a digital library of primary source data than do their students. If the goal of a digital library such as ADEPT is to align activities of faculty and students, then finding ways to represent "real scientific data" in ways interpretable by students is essential. The tools and services associated with a digital library for teaching geospatial knowledge also must support commonsense models of geographic reasoning, as explicated in "naive geography" (Egenhofer \& Mark, 1995).

\section{Research Method}

Throughout the ADEPT project, we have employed a variety of formative and summative methods in the iterative design and evaluation of the ADEPT system. The study reported here is based on interviews with nine faculty members of one department of geography and supplemented by 
data from interviews with four faculty members from two departments that were conducted about 2 years earlier.

\section{Participants}

We invited geography faculty who were currently teaching one or more undergraduate courses to participate in an audiotaped semistructured interview. The faculty was from one geography department with 21 geographers (18 male, 3 female). Nine of 21 faculty members participated in this study. Six respondents were physical geographers and three were human geographers (8 male, 1 female.). However, at least one of the physical geographers could also be classified as a human geographer, as is discussed in the Results section. They represent the ranks of assistant, associate, and full professors.

Interviews with four physical geographers who deployed an earlier ADEPT prototype in their classrooms were conducted pre- and postdeployment. These four faculty members consisted of two at each of our participating universities; all four are male. Two subjects participated in both studies, which were conducted about 2 years apart (2000 and 2002).

All nine subjects in the primary study are drawn from one department, which is in the Social Sciences Division of the College of Letters and Sciences. Related departments such as geology and atmospheric sciences are in the Physical Sciences Division. The Department of Geography at our other participating university is located in the Division of Mathematical, Life, and Physical Sciences of their College of Letters and Sciences.

\section{Interviews}

Interview questions in the information-seeking study were intended to address the following research objectives:

1. Identify and describe faculty information needs and information seeking in support of instruction.

2. Compare and contrast information needs and seeking in support of instruction with information needs and seeking in support of research.

3. Identify and describe tools used when searching for instructional materials.

4. Identify and describe content chosen for instruction and the process by which they are selected and evaluated by faculty.

5. Analyze how instructional media is arranged prior to presentation.

6. Compare the choices of instructional content with the presentation of geography concepts in the classroom.

We interviewed faculty members during an academic term in which they were teaching a lower-division undergraduate class to ensure their description of their experience was current (see Appendix A for interview questions). Interviews were conducted in each faculty member's office so we could observe them in their working environment. One interviewer and at least one note-taker participated in each interview. Interview questions were open-ended to allow faculty to describe their experience in their own words. Probes and follow-up questions were used for clarification and amplification. Interviews lasted from about 30 minutes to almost 2 hours, with the average length being about 1 hour. They were tape-recorded and later transcribed.

The interviews conducted predeployment of the earlier ADEPT prototype addressed faculty members' views of the field and their pedagogical goals. The instrument consisted of 15 open-ended questions (see Appendix B). Here we report only data about the scope of the field of geography and choice of data sources, which complement the current study and were not reported elsewhere.

All results presented here are drawn from the informationseeking study of nine geographers, except where specifically noted that the data are from the earlier study on the ADEPT alpha-prototype deployment.

\section{Coding}

Two coders each read two of the same transcripts and looked for emerging themes in the data (see Appendix C). Once a consensus among themes was achieved, a third coder was trained. All three coders coded all of the transcripts and resolved disagreements through consensus. The predeployment interviews were coded with the same themes by one member of the same coding team. Additional codes were established to identify statements about geography as an information-intensive discipline and general statements about the impact of information technology on students.

\section{Results}

The faculty interviewed represent a wide range of research interests. In physical geography these include climatology, geomorphology, ecosystems, environmental change, historical geography, and desertification. Research areas of the human geographers in our study include privacy, environmental change, and the culture of specific regions. Faculty in all specialties search for maps and images, with some differences in information-seeking behavior between physical and human geographers. This is a group of active information seekers, gathering resources from a wide array of print and electronic sources on a regular basis. Most are able to articulate their information seeking in support of research better than they can explain how they seek information for their teaching. In most cases, the teaching and research activities appear to reinforce each other. While pursuing research materials, they encounter items of value for teaching. Conversely, some try out ideas for research in their teaching, so the information they gather for a course may serve both purposes. Our study addressed only undergraduate courses that these faculty are currently teaching; practices may be different for graduate courses.

Although the distinction between physical and human geography is often viewed as a dichotomy, it is apparent from our data that these specialties exist along a continuum. We attempted to recruit a balanced sample of physical and 
human geographers and originally classified the participants as five physical and four human geographers. One subject was initially grouped with human geographers due to his historical research, which relies heavily upon archival sources commonly used for cultural topics. However, upon closer inspection, we decided this subject was more appropriately classified as a physical geographer because he teaches the introductory undergraduate course in that area. Given that our research focuses on teaching, a classification based on teaching specialty was chosen over one based on research area. The other three faculty members classified as human geographers teach introductory undergraduate courses in that area. Despite having only three human geographers in our sample based on this classification, some differences in information-related practices between human and physical geographers are apparent.

Results are organized into themes that represent our findings from this exploratory study.

\section{Scholarly Inquiry in Geography}

One of the continuing questions in the ADEPT project is about the nature of knowledge in the field of geography. What are these geographers' epistemological views of their field? What do they view as sources and types of geographic knowledge? How is geographic information used to solve geographic problems? What aspects of geographic inquiry do these geographers want to convey to students in their introductory courses?

The pre-ADEPT prototype implementation interviews conducted 2 years earlier attempted to address these issues directly. Although all four subjects in that study were physical geographers, they were articulate about the nature of knowledge across their field. One subject was particularly comprehensive:

Geography is the study of a spatial distribution of most any feature on Earth's surface. It's broken into two major components. ... Human geography deals with the differences in culture as far as culture [is] distributed across Earth's surface. ... The human geography interacts, intersects with physical geography - which is the distribution of climate and geology across the Earth's surface-in many ways, because humans make their living off of the land to one extent or another, and the land and its ability to produce sustenance for humans varies in direct relationship to climate and geology and other factors. field:

Another subject emphasized the integrative nature of the

Geography is one of the only disciplines that encompasses both physical and human cultural and societal concerns. It's able to thread together a number of different disciplines under one hat.

Yet another subject addressed the systems orientation of the field:
We're interested in the pattern as well in the process... geography [is] a discipline that synthesizes so that there isn't a focus just on an item of research data, but how that fits into the whole network ... a system is an important concept to convey, because there's the whole thing and then there's the interaction.

Although we did not ask the same questions of the nine geographers in the information-seeking study, we elicited related responses on the nature of scientific questions. Our physical geographers draw upon a variety of scientific data and theories:

within each framework, there is generally a scientifically and internationally accepted body of information that has to be conveyed.

The same physical geographer offered a rich example of integrating numerical data into diagrams as a means of explaining geomorphological processes:

Last week, for example, I was discussing with the students the ... sources of sediment that are available on the coast from river erosion, from cliff erosion, from coral reef destruction, and so on. So I just took the whole blackboard and worked it up from scratch in front of them and had them follow it through, giving them numerical values for rates of erosion and rates of sediment transport and literal drift whenever it was relevant. So after about half an hour they had a three-dimensional diagram in front of them in which they have the information.

Our human geographers take a somewhat different approach to intellectual inquiry in the field:

the first half of the class we ... try to deluge them with a set of concepts. In the second half of the class, the idea is to try to get them to understand particular topics and then to do a project that involves another topic and analyzes that topic ... [What] I want them to understand at the end of the class ... are questions like, "What does privacy mean in this context?" "What's the difference between privacy and surveillance and confidentiality and secrecy?" "What are the differences now and how do those differences emerge and how do those differences get articulated in the context of some particular social issue?"

Another human geographer offered this example of inquiry:

I talk a lot about geography of Los Angeles, but the goal isn't to learn about Los Angeles specifically. The goal is to take their experience of Los Angeles and to then be able to ask questions about urbanization in other parts of the world, ask questions about something as simple as the use of recreational parks as public spaces.

\section{Knowledge Sources and Information Technology in Geography}

The four interviews with physical geographers conducted in 2000 prior to classroom implementation of the ADEPT 
alpha-prototype provide insights about sources of knowledge in geography and about the value of geospatial information technologies for students' learning.

One geographer commented on the use of formal representations in geographic information systems:

[GIS] allows a complexity of analysis with multiple layers of spatial information that is not normally possible to do with paper and hardcopy maps. It's very difficult both conceptually and physically to look at 10 different maps for the same area and truly understand the interrelationships and overlapping and intersecting qualities between them... I think [GIS] aids students to truly get it.

Another physical geographer discussed the origins of geographic knowledge:

in my field [climatology] ... we have to make observations, instrumental observations ... over space and over time. We analyze the observations using physical principles: physics, chemistry, statistics. We come up with an idea of how it is, how the climate is what it is, [how] the weather is what it is. We go from observation, to data collection, to data analysis, to information... Observation is always key, not instrumentation. But observation as in seeing things and being able to make the link ... I couldn't do what I do without computers.

Yet a third physical geographer discussed the role of GIS and digital data at length:

Recently, the whole world has changed. We have satellite imaging, we have information systems, we have people doing extensive research and producing materials, we have government agencies, the census, the U.S. Geological Survey, NIMA for the defense agencies, etc., etc. Just about everyone and everything needs geographic information. To fight a war you need it, to fight medical epidemics you need it, to do anything about environmental hazards you need it.

There are certain areas of statistical geography that can only be taught by people having hands-on experience with statistics. One of the things we're coming to realize is, a lot of the phenomena in geography are dynamic. With the aid of computers, we're able to do more and more computational models of processes unfolding. How people do way finding, for example. How the processes of natural river development occur. How systems of cities develop over time. Looking at traffic flow problems. This dynamic modeling is difficult to understand, unless you can see simulations of the models. So more and more, it's really critical to get into the students' minds modeling concepts, for simulation time-dependent models, and show them the results of such modeling and what changes in model parameters and form do. I think this is one of the big thrusts. Not only illustrative materialvisuals are absolutely critical, words don't do justice-but also lots of simulations. Also, things like virtual reality, increasingly. Fly-throughs and things like this. Again, the whole world of modern technology is opening out so many ways.

\section{Primary and Secondary Sources in Geography}

Another way we approached the nature of inquiry and knowledge in geography was to elicit their definitions of primary and secondary data sources. The comparison was a familiar issue for the human geographers, and we got explicit responses. It was a less familiar question to the physical geographers, at least two said they had not thought about it before.

Most of the physical geographers in the study said that primary data is somehow raw data, whether numeric, images, or field notes. Five of these subjects made similar comments:

I also think of field data, which I often use as being primary. Generally if it's been edited, published and analyzed I think of it as secondary data.

But the simple answer is that ultimately the primary source of information in my field is in the field. It is not in libraries. It is not in the laboratory. They come later, or in the case of libraries, they may come before. But the primary source is in the field.

I think the first primary source would be some sort kind of image, either from satellite or from some people's research.

A primary source is the individual or group that created the coverages of its GIS or processes the images of its remote sensing.

I would say these satellite data are definitely primary data ... These would be primary data. They're raw satellite data. They haven't been interpreted yet.

The two physical geographers who struggled with the distinction initially said that journals were primary sources, but changed their minds when asked for definitions of secondary sources. Then each said that raw data (in the forms noted above) were primary and that journals were secondary sources.

All three of the human geographers defined primary sources as being raw data that has not been analyzed by anyone else:

[primary sources] could be field observations of some kind, be it physical field observation or human-oriented. But it would have to be data that was collected directly by a researcher or an observer. It wouldn't be derived from some kind of secondary source.

My primary interest is in the way in which people construct and inhabit places, so at least in the context of that definition, a primary source could be something ... it could be some kind of visual or other account made by somebody doing field work.

But it could be modern in a sense of just raw data from a census or interviews. It could be field observations. Geographers tend to link primary sources with field observations. 
The latter of these three subjects added a historical perspective to the definition of primary sources in geography:

[A primary source is] something that comes from the particular era that's being studied. It's either something that's written about that era by an author who lives in that particular time. It could be an artifact from that era, a tool of some sort. We also include replicas of material from different periods. And in geography I guess you could use the same kinds of definitions. Replicas of maps from a particular period.

The subject who was reclassified from a human to a physical geographer views field notes and archives as primary sources:

I try to get them to read expedition notes. Dave Portello who came up the California coast in 1769 ... The Lewis and Clark expedition ... trying to get them interested in some of those original notes. I might use things like that for my own research.

I have three main sources. The first of these are historical/archival. I actually think of myself as an historical geographer, so I have spent a lot of my career in archives. And I expect my students to do that, too.

These geographers know the information resources of their field very well and make extensive use of them. We asked them to provide examples of resources and tools they use regularly. Our nine respondents listed several dozen sources in total, which is not an exhaustive list of the sources available to them. Table 1 categorizes the sources and types of information mentioned by our subjects. Entries in the table should be read as examples and themes, rather than as numerical counts or a strict classification. Some respondents mentioned only a few sources, while others generated long lists; thus counts by faculty member or division by specialty are not meaningful. Some entries are listed in more than one category. For example, government agencies are an important source of datasets (e.g., satellite data, remote sensing). When geographers said they used these agencies to obtain datasets, we categorized these uses as an institutional source and as a data type.

Differences between physical and human geographers are particularly striking in their use of information resources for teaching, a topic that will be explored in more depth in a forthcoming paper from these data (Gilliland et al., in preparation). All of the physical geographers appear to assign textbooks for their introductory courses, although the choice of text varies by instructor. They also vary in the degree of reliance on the text. One physical geographer follows the text very closely and uses minimal supplemental materials, while the others actively seek complementary images, maps, data, and examples. The human geographers are less likely to assign texts in introductory courses, instead assigning multiple scholarly monographs or constructing course readers from journal articles and other sources. The latter courses are built more around case examples, which require a wider array of supplementary materials for classrooms and laboratory sessions.

\section{Information Seeking as a Regular Activity}

Seeking information is a regular activity of the geographers in our study. They are continually scanning their environment for documents, images, datasets, ideas, people, and resources that may be useful for research or teaching. They are active information seekers, deliberately searching for items of interest. They are also passive information seekers, grabbing an interesting image or tidbit spotted in the process of other reading, browsing, or leisure behavior. Most of the behaviors these geographers reported are typical of prior studies of information seeking for scholarly research, such as browsing library shelves, browsing personal collections, following citation references in articles, asking colleagues, visiting new book and new journal issues' shelves in the library, and attending conferences. All of our subjects use online sources, and many continue to be heavy users of campus libraries and print sources.

We found less evidence of behavioral differences between physical and human geographers with regard to regular information-seeking activities than in some other areas. All are browsers; all have favorite Web sites. One from each group mentioned that their library visits have declined as more sources become available online. Physical geographers mentioned how they use the campus libraries for research and teaching; some were specific about encouraging their students to use the library. Physical geographers made more mention of specific Web sites where they find useful data sources; often these are sites provided by government agencies or professional societies.

for research . . . basically I know where to find . . . the information and what's current because I've been using it for so many years, so I know the coming stage of research.

I have a general idea of where to find information. I go to NOAA. [If] I want to get information for global warming, I know that NOAA is the agency that collects the information.

The human geographers were more explicit about their use of the university library, which is located almost next door to their offices. They mentioned that they walk the physical space of the library and use serendipity to find items nearby. They browse shelves by call number. One subject listed his favorite areas by Library of Congress Classification numbers:

To me the most important sections are HC, JC, and sometimes parts of G. G is the geography letter under the Library of Congress system. A lot of the things I'm interested in are under $\mathrm{HC}$ and are discrete segments or sections of the library. I don't spend much time in the G section.

They walk up and down library aisles. One mentioned looking at shelving carts near library elevators; another 
TABLE 1. Information sources and data types.

Sources of information (personal, institutional)

- Personal collections (multiple media)

- Libraries: Catalogs, documents, images, datasets

- Universities: Research sites, course syllabi

- Government agencies: Web sites and datasets (e.g., Dept. of Commerce, European Union, population bureau, Census, USGS, NCAR, NOAA, National Snow \& Ice Data Center)
- Professional societies

- Publishers, media outlets (e.g., video rental stores, PBS, Discovery Channel)

Databases, digital libraries, catalogs

- Web sites

- Library online catalogs (e.g., Orion2, Melvyl)

- California Digital Library: Catalogs, journal databases, archives [Although none of these subjects mentioned the CDL by name, they did mention specific resources that are provided to them via CDL.]
- Journal databases (e.g., Lexis/Nexis)

- Search engines (Google)

- Directory sites (Yahoo)

- Aggregators (Lexis/Nexis)

- Photo archive collections

Data/information types

- Images (e.g., photos, satellite images, drawings, plots, from any source)

- Maps (e.g., topographic, geologic, demographic; from any source), atlases

- Published data sets, survey data (e.g., geology surveys, census data, TIGER files)

- Scholarly journals (e.g., Science, Nature)

- Books, reference books

- Articles in popular press, popular economic press, general purpose magazines (e.g., Economist, NYT, Wall Street Journal, Financial Times, The Economist, LA Times)

- Videos (e.g., moving images of geological phenomena such as waterfalls, floods, earthquakes; instructional videos (e.g., from Open University); documentaries, movies (e.g., Roger \& Me))
- Unpublished materials

- Land coverages (1) A term that refers to a layer of spatial data within a Geographical Information System. (2) In remote sensing, this term is often used to describe the extent of the earth's surface represented on an image." (GIS Dictionary, 1996)

- Other people's course syllabi

- Data \& marketing information sent from company sources

- Trade magazines

- CDs produced by academic societies (Geomorphology Specialty group of the Association of American Geographers; may contain maps, images, simulations, datasets, text, documents)

- DEMs (digital elevation models)

- DOQQs (Digital Orthophoto Quarter Quadrangle)

Personal data collections

- Expedition notes

- Historical archives
- Field/field work

- Textbooks

People

- Colleagues (as scholars or as instructors)

- Speakers at conferences, guest lecturers

Software and other computer-based tools

- GIS software (e.g., Arcview, Arcinfo)

- Remote sensing software (e.g., Erdas Imagine, Envi)

- Edge software

- Software CDs that come with textbooks

- Commercial statistical packages

- Satellite image analysis software

- Web site creation tools
- Digital cameras

- Image manipulation tools (resizing, captioning etc)

- Statistical software

- Word processing software (converts it to html)

- Computer

- Map making tools at NOAA Web site diagnostic center

Non-computer-based tools

- Camera to take my own pictures

- Photocopier

- Laser printer

- Powerpoint
- Pen/pencil/paper

- Transparencies/overhead projector

- Calculator

- Slide projector mentioned visiting new journal shelves in the library and making copies.

I go to the library probably at least once a week and sort of wander around in the new journals section. And I go to three or four sites within that section regularly. I know where these journals are and what shelves, just to see if something new came in this week.

While all of them appear to be frequent users of the World Wide Web, they do have different ways of approaching the 
Internet. Several listed favorite Web sites that they go to frequently, which they bookmark. Frequently mentioned sites, especially by physical geographers, are those that provide geographic data, including National Oceanic \& Atmospheric Administration (NOAA), United States Geological Survey (USGS), Environmental Protection Agency (EPA), and National Center for Atmospheric Research (NCAR).

Other geographers mentioned using search engines to locate sites, then searching within sites for the information of interest. This quote is from a human geographer:

I go on the Web quite a lot and I usually use Google or Yahoo or something. I don't just put in search terms. Usually I already have some archived name or some kind of destination. And then when I get to the destination that's when I'll start using the search terms.

These geographers also vary in whether they tend to browse or tend to search by keywords. One human geographer said, "I tend to think in terms of words" (when searching through sites). Another said, "I have to look at it thematically to get close to what I want because there's just so much that can be done if you organize things geographically."

They also have a variety of habits for searching library catalogs and journal databases. One of our physical geographers cleverly used the online catalog to skim journal contents. He searches for known journal titles and then browses article lists within these journals. However, this subject did not seem to be aware of indexing and abstracting databases in his field that would have provided more search features and may have included abstracts or full text for these same journals.

Iterative cycles of searching and using information resources are common. They follow links in Web sites, follow citations in print and online journal articles, and look up books in the library catalog that were mentioned in reviews. Specific behaviors mentioned include "reading chapters written by others while editing a book," "reading to stay current," "keeping lists of interesting topics," "reading, writing down ideas, looking at references and reading those," and "figuring out what's interesting from the literaturesearching bibliographies, searching bookstores, reading journal reviews."

The geographers in our study are active members of their invisible colleges, relying on their colleagues as essential sources of information. Several commented on the importance of scholarly and professional meetings. At least one said specifically that these channels are essential "because published information is too late."

\section{Searching for Images or Maps}

Where geographers vary from scholars and teachers in many other fields is their reliance on images and maps. Images and maps are much more than illustrations; they are essential data sources and essential products of research activities. Geographers of all specialties in our study analyze data (e.g., remote sensing, satellite data, field observations, historical archives, popular sources) to produce images and maps. They also search for images and maps created by others; these may be used as data sources for further analysis, used in their present form, or modified for other purposes (e.g., resized, cut, annotated, additional data added).

Maps and images are most commonly indexed by location, whether by latitude and longitude or by place name, in both digital and print sources. However, our geographers often sought images that illustrated a process, activity, or concept. As experienced information seekers, these faculty members have developed clever ways to locate visuals of interest. Here is an example from a human geographer:

I'm always looking for images. I'll look anywhere. I subscribe to a number of magazines that I use for images, charts, and maps. I look on the Web; I look at other people's lectures. If I see a lecture that I like I'll ask somebody for a slide from it, if I think I can use it.

One of our physical geographers offered a particularly challenging search example:

Last quarter, I spent almost the whole quarter trying to find two images which can be used for the lab ... I want two images that are at least 10 years apart, to show the land cover change over 10 years. That was very difficult.

A human geographer provided an example of what to do with mapping data once found:

The Census Bureau now has done this kind of thing but they're about the only people you know where you can mess around with ethnic distribution maps or things like that. Or put in your own criteria or cut-offs-you know like more than $13 \%$ of the population in this zip code are Chinese born. It lets you do that now with those maps.

The physical geographer who relies on archival sources offered a salient example of retrieval difficulties due to lack of indexing:

Well it turned out in a really wet year that those streams eroded badly. I knew what they looked like now, but I didn't know what they looked like 5 or 10 or 20 years ago. My student and I just kept prowling around down in the county and city archives and finally we just came up with a map, almost by accident, of this particular stream area done in 1976. It was mapped to an incredible detail, and it was just exactly what we needed. It was like a gift from heaven.

Characteristics such as these are rarely indexed in image collections, resulting in extensive browsing and serendipitous discovery on the part of our geographers. Thus, the geographer intended a concept search but the topic of interest was not described or cataloged by the terms searched.

Most of the geographers in our study capture images or maps as part of their own research, whether via cameras 
(film or digital), or via computer generation from data sets (e.g., weather patterns). By mid-career, many have built substantial image collections of their own, and searching them is part of their information-seeking activity. One of the human geographers had a large light table for sorting slides as a prominent fixture in his office. Others had physical and digital files of various sorts of maps and images. Often their office walls were adorned with maps, images, and photographs associated with their research topics.

\section{Information Seeking for Research and Teaching}

We asked our geographers about their information seeking for research, for teaching, and for comparisons between these activities. Four themes emerged from answers to these questions: (a) they found it easier to articulate their research activities than their teaching activities; (b) research and teaching activities were viewed as mutually reinforcing; (c) they continually scan their environment for information sources and glean for both purposes; and (d) they rely on their own research data as information sources for teaching.

Articulating information-seeking behaviors. When we asked these geographers how they sought information in support of their research, all had ready answers. They could tell us how often they went to the library, what they did there, and which Web sites and databases they searched most often. They demonstrated some of their search methods to us in their offices - the use of online resources, stacks of manila folders, and slides arranged on light tables. They generated long lists of favorite resources and common practices, as discussed in previous sections.

In contrast, the answers were less forthright when we asked about their information seeking in support of their teaching. All had answers, but few appeared to have articulated this behavior before, and the responses were more rambling than those for research topics. Often we needed several follow-up probes to elicit explanations of how they gathered resources to use in reading lists, lectures, labs, and assignments.

Physical geographers often rely upon online sources for supplemental teaching materials for their undergraduate classes:

Sometimes [I go to the library]. Not for class things, actually. I find I don't need to because so much is available right from the computer and then if I want to I can print it out. You can get very lazy.

Physical geographers also use the library for teaching materials:

Yeah, I'd say a lot. You sometimes need something in particular, for some images. Sometimes the books are too brief in their descriptions for students, ... . so I have to go to the library for something general, for copies and figures, so that's why you see me in line. ... Basically I search here [OPAC] for either books or journals or maps, and they have other audio-visual materials, but I really don't go there.

Another physical geographer relies on the Web for teaching resources, but has some concerns about the reliability of those sources:

I find more and more that I use the Web a lot. It's like the first place to start. For instance, for the seminar that I was teaching, the students went first to the Web for the different topics that they had. And you'd be amazed at how much information is there. Of course, so much of the information that's out there is not easily verifiable. So it's a place to start, but not necessarily to finish. But you can get a lot of definitions. You can see how much interest there is in a topic. And you can find reliable sites through that; if you know what to recognize, you can find NOAA sites, you can find a host of reliable sites. But once they've gone there, they have to go back and try and find academic sources as well, because you can't trust everything on the Web.

One of the human geographers mentioned his reliance on popular sources for teaching materials:

Particularly with the lower division course, materials from magazines and business sections of newspapers. Also from Web sites. And from sort of general purpose magazines. Magazines like Foreign Affairs, for example, which comes out six times a year. I read that very assiduously.

Mutually reinforcing activities. When asked to compare their information-seeking activities for their research and teaching, five of the nine geographers stated some specific differences. Even the four who initially said these were a common activity pointed out a few differences in their own practices. A consistent theme in the nine interviews is that seeking information for research and teaching are mutually reinforcing activities. Geographers spot useful images or examples for teaching while searching for research materials. Conversely, some try out research ideas in class, so that resources initially used in teaching may become research documentation. Overall, research influences teaching more than vice versa.

These quotes are from physical geographers about information seeking for research and teaching:

My teaching and research are intimately interlocked. Even at the undergraduate level, I draw examples from my own research and that of others. But for my own research specifically, to illustrate points around a general principle. I probably wouldn't teach a course in which I was not conducting research at the same time.

I try to bring these things in; I don't want their eyes to glaze over.

The fact is that in a university, essentially what you are paid to do is research .... it's a cost benefit analysis. You ask 
yourself, "Well I could spend the next three days revising some lab, or revising this course or whatever, or I could work more on a paper." Where's the reward? It's not in revising the class. All you get for that is personal satisfaction.

If I was going to be honest, I'd [teach] based on what data is available. So if it's a situation where I have some data of [his research topic], I'll use that. I do spend a little bit of time looking around trying to find stuff, but have been historically a little pressed to publish papers. So I haven't put as much into teaching as I probably should.

It's the same thing. But I'm more interested in my research.

The comments of a human geographer also capture the reinforcing relationship well:

I spend a bit more time in these popular sources than I would if I was doing research ... In the Economist, for example, there's lots of reporting that has references to more academic or scholarly sources ... I find more serious research articles even in these sources where I'm primarily looking for things for class. So for me there really is sort of a virtuous circle I like. All my teaching and all my research are really very closely bound together... In a research university that should be the way ... You know now I do this to pay the bills and then I do my research. There should be a connection. And I think your enthusiasm too, for the materials, is probably driven by the fact that this is something you research too.

This human geographer (quoted above and below) is the author of a textbook. In his case, good examples for classroom instruction also are potential textbook illustrations.

One of the reasons that I'm always looking for new examples and new cases isn't just because it's illustrative material for a lecture, but also, it may turn out to be a good example to slip into the next edition of the textbook. And it may also be something that helps me kind of think about a particular theme that I'm addressing in a research paper.

These are the comments of a different human geographer:

So often it's done in combination with other things I'm doing, when I'm doing something else and then I think, I can incorporate this in this class. So there's not a real break for me.

Scanning for research and teaching sources. Geographers are always on the lookout for good images, maps, illustrations, animations, or other resources that they can use to illustrate points in class. These are often encountered serendipitously in the process of seeking research materials or in the process of current-awareness scanning. They frequently commented on the value of serendipity and knowing it when they see it. The following two comments are from the same human geographer (a different individual than the one quoted at length in the prior section):

The other thing about [Introduction to Human Geography] though is [that,] because I've taught it a number of times and
I know what I'm looking for, I'm preparing for it all of the time, because I'm looking for things all the time ... Especially better reading material, material that's got contemporary issues that illustrate a point.

My searches are rarely systematic ... Fortunately I'm able to teach close to what I work in-my research and my travel — and I'm aware of it all of the time. It's just kind of an organic integrated whole.

Use of research data in teaching. All of our geographers draw upon their own research files in support of their teaching. They gave us a number of examples and reasons for doing so. One reason is that they tend to teach in their research areas, even for introductory courses. They draw from the material they know best. Their own files are readily available at little or no direct cost. As mentioned above, these geographers have assembled substantial collections of images and maps over the course of their careers. Working with their research data in teaching reinforces their research thinking, and may generate new hypotheses or theories.

Cost considerations are another reason for relying on research data for teaching. Often these datasets are very expensive. Some of our geographers write grants to purchase datasets for their research. They can re-purpose these data for teaching, but they are unlikely to get sufficient instructional funds to purchase datasets specifically for classroom use. A few examples from physical geographers illustrate how they acquire data for multiple uses:

I write grants to get satellite data from other countries, either to get access to the data or money to buy the data. Or the US satellites are generally available at nominal cost to all investigators. There are established sources to get this stuff.

You can buy images online that are archived, but a lot of times they are expensive. So I would say price is first.

[Referring to remote sensing data.] You want everything, ... And nobody, nobody, I think can afford to get the older data ... So the data ... depends on how much information you want to get and how much money you have to get it. Nobody will get enough.

\section{Desiderata}

Throughout the iterative evaluation studies of ADEPT we have asked our prospective users what content and functionality they would like to have in such a system. Such questions rarely yield useful data when phrased in the abstract, as they elicit responses of the form, "What can you provide?" This line of questioning was more effective in this study, as once we got them thinking about their information-seeking activities, they could tell us what did or did not work well, and what else they might like to have.

Typically, they wanted more access to useful images and maps, and they wanted them described more fully. Geographers of all specializations mentioned the need for more 
conceptual or thematic searching capabilities on maps. These quotes are from two different human geographers:

At least two things would be very helpful. One would be to try and organize material by types of course. And another would be ... more by themes, ... for example of maps [to] represent certain kinds of . . . economic geographical concepts. Or a certain kind of physical geographic concept. So more concept organized knowledge.

I'm not a big latitude and longitude person. I'm kind of a place person ... use of language ... spatial systems ... and institutional [factors] . . . the language that kind of extracts people from their every day experiences.

Physical geographers also may rely on concepts rather than specific geographic locations:

I tend to think in terms of words. So moving through certain kinds of key words. Is that the sort of thing you mean? Okay. That's where I always start.

Q: Are the keywords concepts? Are they latitude and longitude?

R: They're concepts. Latitude and longitude is too precise, unless you're given ranges. And then once you start in ranges you may as well use a concept. After you've gotten past the concept, if you've got some feedback from the machine once you've plugged in your keyword, then you can start honing down into specific locations or something like that. But I would start with a keyword.

Concern over the cost of images and maps is a continuing issue, as expressed by a human geographer:

It would be good if more sites were . . free . . . That's been a negative change recently. I find that more and more you are closed up and it needs to be available. The Web has become more commercialized than what it was the first few years ... More and more of them seem to be requiring you to subscribe and provide all kinds of information about you in order to gain access ... so I thought I'd like to go back to the even more sort of free, easy, more open source.

They are interested in teaching materials created by others, as the same human geographer quoted above comments:

If [users] could maybe also ... consult with people who teach courses like this to arrive at the kind of materials that people are monitoring [or] keeping tabs on, I think that would be very useful. It would mean you could just go to one place instead of doing all this searching, in sort of a ramshackle sort of hit or miss searching. It would join together the conventional wisdom of all the people who are teaching things like this. That would be fantastic.

They want to be able to manipulate the maps and images once they obtain them. This physical geographer also commented on how information technology might assist in geographic reasoning:
I can look at a map and I can look at the contour lines and I know I'm going up hill or valley or whatever. Some students have a hard time with that. I am sure there are exercises that we could create so they can walk across the terrain and see it. You're going to have digital terrain maps ... Or digital elevation maps. They can do their calculations from it. They can look at particular exaggerations. So we move from what's on the map to the idea of scale... Another one would be in looking at winds in the global system. Or we're looking at what happens as the earth turns. There's a lot of things that are out there already, but they're not in any one place that I can actually bring into the class.

A human geographer had similar interests in retrieval and manipulation:

The ability to ... download images and produce fairly high quality images. And also to kind of mess around with them a bit if they aren't exactly what you need. So you can fiddle with them. So, I suppose that's a sort of interactive [capability] which would be great. And that's totally missing from all of the sources I use at the moment. There's not a single source of the kind of material I use in particular where I can go in and switch, for example, the way that ... the data is represented on a map.

One physical geographer wants "tools to think with" in a digital library:

I'd like it to be able to tell me if I search on something, what else is there that I might be interested in, given the topic I'm asking about. In a way, I guess I want it to help me think. Which isn't unreasonable because every database management [system] has its own idiosyncrasies that are not necessarily in sync with mine.

A human geographer had similar interests, though phrased differently:

The kind of thing that would be really useful for me would be to be able to pick out some area . . . and to find out what's happening [for example with] medical privacy ... everything from what's happening to a health delivery system of HMOs to ... the consolidation of pharmacies ... information systems for pharmaceutical advertising. Then the regulation of various ... torts and issues about what could be reported in the newspaper . . . tons of things. It would be nice to be able to do a search that would lead me off [in new] directions.

Another physical geographer who is a skilled artist does not expect computer-based tools to be able to support his abilities to draw or manipulate images and maps:

As for manipulating them, massaging them, putting them on to a screen and playing around with them, no. I'm not that adept at that kind of thing yet. I wish I was more adept. The problem is that I'm something of an artist as well, you see, and I always regret that computers were invented. Because for me to draw something on a board three-dimensionally is more of a challenge than having somebody else do it for me with a canned program or something like that. 
Having observed the above faculty member teaching the introductory course in physical geography, we can attest to his artistic ability. He often came to class 15 to 20 minutes ahead of the students to start drawing diagrams on the board using multiple colors of chalk. No digital library or other computer-based tool is likely to produce as lucid an illustration of a geomorphological structure or process as can a senior scholar with sophisticated chalk skills.

\section{Discussion}

The results of this exploratory study suggest a variety of implications for the design of digital libraries for undergraduate education, despite the small sample. The discussion is organized by three themes that emerged from our data: information-seeking activities for research and teaching, content requirements for digital libraries, and functionality and architecture.

\section{Information-Seeking Activities for Research and Teaching}

The information-seeking activities of physical and human geographers in support of their research tracked closely with behaviors typical of physical scientists and social scientists, respectively (Case, 2002; Meadows, 1998). Faculty in our study track the new literature in their fields, browse familiar sections of the library, bookmark favorite Web sites, follow citation links, attend professional conferences, and receive sources and references from their scholarly peers. All of the geographers seek maps, images, and illustrations for their research and their teaching. The specifics of what they seek vary by research area and course content, as would be expected. Physical geographers are concerned with climate and geomorphology, while human geographers are concerned with social activities associated with places.

The dual work roles of research and teaching are sometimes complementary and sometimes competitive, confirming earlier studies (Jenkins, 2000). In information-seeking, the roles appear to be complementary and mutually reinforcing. Faculty report that they often find useful items for teaching in the process of searching for research topics, and may also find research ideas or resources while gathering information for teaching. Their personal collections of research data, maps, and images are mined for teaching examples. Several faculty mentioned research insights that arose from teaching. However, if faculty combine their information-seeking activities for research and teaching, and if research needs are the main driver of information seeking, will they make use of a digital library that provides only teaching resources? This is a key question for ADEPT and for digital libraries of teaching resources. Our results suggest that some faculty would search a digital library that contains teaching resources, especially if organized by teaching concepts. But a repository of teaching content alone would not be sufficient. The ability to contribute their own resources to a digital library is essential, given that they draw heavily upon personal research collections for their teaching.

\section{Content Requirements for Digital Libraries}

Our results confirm that maps and images are essential resources for teaching and research in geography, both physical and human. Another finding is that geographers are fairly consistent in their definitions of primary and secondary sources. Primary sources are raw, unprocessed data or images. Once analyzed by a researcher or research team, they become secondary sources for others. Secondary sources such as conference papers, journal articles, and books are also used by our geographers in their research and teaching. They appear to have adequate access to such secondary resources. Indeed, the University of California is known for the strength of its library collections, in both print and digital form. Their desires are for more primary sources such as sensing or census data, images, maps, and photographs. It is these resources for which they have an almost insatiable need, and for which they often find the searching capabilities to be inadequate. The cost of acquiring primary source data is another barrier to their use in research and teaching, especially for those who rely on remote sensing and climate data. Human geographers also noted the increasing cost of data and the decreasing amount of free resources (of adequate quality) that seem to be available.

A corollary to the finding that faculty's greatest need is for primary sources is that primary sources are an essential ingredient for inquiry learning. If students are to learn to "think like" or "work like" scholars, they need opportunities to explore the same primary sources used by scholars (Borgman, 2004; Munby, Cunningham, \& Lock, 2000; Posner, Strike, Hewson, \& Gertzog, 1982). Rich collections of primary sources such as the Alexandria Digital Library exist, but they lack tools and services for teaching applications.

\section{Functionality and Architecture for Digital Libraries}

We highlight four issues of functionality and architecture for ADEPT that arise from this study: (a) searching for maps or images by concept, (b) creation and management of personal digital libraries, (c) digital libraries as shared spaces, and (d) capabilities to manipulate data and images.

Searching for maps or images by concept. Georeferenced digital libraries are typically organized by location on the earth, both by coordinates (latitude, longitude) and by place name, with a gazetteer to translate between place names and spatial locations. The full name of ADEPT, the Alexandria Digital Earth Prototype, incorporates the location-based model in the "digital earth" metaphor. Maps and ideas associated with a physical place are the organizing principle of the field of geography, and yet the faculty in our study consistently spoke of the need to search for maps, images, and data by concept or theme. This finding does not imply that 
they reject the need to search by location or place name. Rather, it is more likely that they find those capabilities to be adequate. A search might start with a location or place, but then ask about concepts, structures, or processes associated with that place. Alternatively, a search may be primarily about a concept, whether a geo-morphological structure or process or a social concept such as privacy or public spaces. Drawing a sharp distinction between searching by place and by concept risks obscuring the depth of expertise of these geographers. Their scholarly expertise may include encyclopedic knowledge about which features or activities are associated with particular places. What appears to be a search for a place may be a search for a concept or process, and vice versa.

Undergraduate students and other novices lack substantive knowledge of geography and geographic reasoning skills. Thus, better concept and location searching capabilities based on naïve geography (Egenhofer \& Mark, 1995) should improve students' (and faculty's) access to primary source content and facilitate inquiry learning.

Our interviews and other conversations with geographers suggest that concept-based indexing and other metadata creation are difficult because any image, photo, map, or diagram can have multiple interpretations. The physical geographer who deployed the fullest version of ADEPT in 2002-2003 noted that he often uses the same image to illustrate different concepts in different classes, and he may emphasize different aspects or describe an image in different ways in each of several class sessions. The examples of maps and images given by human geographers are even more abstract. Concepts such as privacy, public spaces, or environmental protection are difficult to index in ways that can be located by future users. Faculty in this study repeatedly described the difficulty of articulating descriptions of images, the importance of "knowing it when I see it," and the value of serendipity. Techniques that facilitate recognition, such as the "gallery" approach (a screen full of "thumbnail" sized images) common in visual arts applications, should be useful. Allowing users to label images with their own metadata also will facilitate browsing, particularly within personal collections. These techniques are already being tried in current versions of ADEPT. Research on image searching in other domains may be particularly fruitful for geographic applications.

\section{Creation and Management of Personal Digital Libraries}

Personal digital libraries have emerged as a core design principle for ADEPT, and this study confirms the value of this approach. Personal research collections are essential for teaching due to relevance, as faculty usually are teaching in their research areas, and due to familiarity, because they know their own collections intimately. Each geographer has his or her own personalized ways of organizing lectures and class materials, whether stacks of manila folders, stacks of overhead displays, Web sites, MS PowerPoint files, or CD-ROMs. Thus, tools to manage and mine research collec- tions for teaching may also be essential requirements for adoption of ADEPT.

ADEPT will need the capability to import information sources in standard formats, including text, images, numeric data, and files from common office software (word processing, spreadsheets, and presentation tools). The import capability is still in development. Until faculty can easily and quickly import the resources they are currently using into ADEPT, they are not likely to find the system attractive.

Digital libraries such as ADEPT should be able to capture whatever metadata already exists on files and images as they are imported. Users should be able to add metadata to their resources quickly and easily. One of the key developments in the current implementation of ADEPT is a concept database that allows instructors to create concept nodes, link them to each other in hierarchical relationships, and populate them with digital objects. The instructor who deployed this version of ADEPT in 2002-2003 constructed a rich concept database for teaching this course (Champeny et al., 2004; see Figures 2 and 3). One of the research questions for the evaluation of ADEPT is how much use other instructors will make of his concept database and how much modification they are willing to do for their own courses and research materials.

Digital libraries as shared spaces. If we focus on the creation of personal digital libraries, will faculty have sufficient incentive to share their collections with others? One goal of ADEPT is to share teaching modules that incorporate primary sources. Geographers in this study expressed interest in the use of teaching materials created by others, and many freely ask colleagues to share lectures and images. Posting lectures, notes, syllabi, and teaching resources on public Web sites is becoming much more common. While the risk of borrowing without attribution exists, the academic ethos is to give credit where it is due.

Faculty appear more willing to share teaching modules than to share primary source data, however. Faculty may use research data in a course prior to the time they publish those data, and do not wish to share them until postpublication. Even after publication, they may be reluctant to share them in raw form. Providing data to others often involves providing the field notes and codebooks that may be difficult for others to interpret adequately. Scientific data are not useful as disembodied numbers or facts; knowledge of the research method and instrumentation are essential for interpretation. These are among many disincentives to sharing primary research data (Bishop, Van House, \& Buttenfield, 2003; Bowker, 2000a, 2000b; Star, Bowker, \& Neumann, 2003; Van House, 2003). While the incentive problem is beyond the scope of ADEPT, we must be aware of these issues in our design.

Another disincentive to sharing that arose in this study is intellectual property barriers. Instructors frequently clip articles and images from newspapers and magazines (print and digital), textbooks, scholarly journals, and even from film and video for use in teaching. As long as the use of copyrighted materials is restricted to the instructor's classroom, 
it generally is deemed fair use for educational purposes (regardless of whether it would pass a strict legal interpretation of "fair use"). However, if those same materials are posted on a Web site, circulated electronically to students, or distributed to other instructors, the interpretation of fair use becomes far more restrictive. Explicit permissions may be required and may be difficult to obtain, in terms of both time and money (Lessig, 2001).

Creative Commons (http://www.creativecommons.org) is currently the most promising approach to resolving some of these intellectual property problems, which are otherwise a massive road block to resource sharing for education. Users can license their content via Creative Commons with varying degrees of rights. They may allow others to use the content only if left intact, only for nonprofit purposes, or to manipulate it, provided the original source is acknowledged, for example. An interim step for ADEPT is to rely on metadata to register copyright ownership (at least at the level of "O.K. to share" vs. unknown) and to use that field as a filter for providing access to materials. This is admittedly a provisional solution to an enduring problem. Other digital libraries, such as the Alsos Digital Library for Nuclear Issues (2004), have made use of the Creative Commons license. ADEPT, as mentioned, contains resources of uncertain provenance, and professors who make course materials available online via ADEPT may not be willing or able to ascertain which portions of their personal collections they are able to share, even when the mechanics of that process (such as posting appropriate metadata) are quite simple.

Capabilities to manipulate data and images. Digital libraries can support information seeking, use, and creation, all of which are of interest to the geographers in our study. Once they locate items of interest, they tend to manipulate them in various ways. They enlarge images, they shrink images, they select sections from them, and they annotate them. Sometimes they use computer-based tools and sometimes they use paper, plastic foils for overhead projectors, markers, and photocopy machines (one of our respondents is particularly facile with the enlargement capabilities on his department's photocopier). They re-compute data to create new maps and new images. The ability to manipulate data and images is at the core of scholarship and teaching in the field of geography. Each individual adds his or her own perspective to the evidence available.

Content manipulation requires complex tools that are beyond the scope of ADEPT. However, ADEPT designers intend to facilitate interoperability by maintaining objects in standard formats that are easily imported from and exported to common data management tools.

Content manipulation may define the intersection between personal digital libraries and shared spaces. Users could maintain their separate personal digital libraries while contributing some or all of the content to the shared space. Others could select from the shared space, manipulate it, and resubmit to the shared space with appropriate tags. They could also keep manipulated versions in private spaces. As usual, the technological challenges are simpler than the behavioral and policy challenges, and we will need to bear these factors in mind as we move forward with the design of ADEPT and other digital libraries with similar goals.

\section{Conclusions}

Digital libraries hold great promise for improving undergraduate education by providing access to primary sources and by providing associated tools and services to deploy those resources in teaching and learning. Geography is especially suited to the educational use of digital libraries because content is plentiful and tools and services to facilitate geographic reasoning are sorely needed. It is also a discipline that can benefit from inquiry learning approaches by making the content and tools of scholarship available to students. ADEPT is an ambitious, 5-year project whose goals are to construct, deploy, and evaluate inquiry-learning capabilities for the Alexandria Digital Library, an extant digital library of primary sources in geography.

The study reported here is one important step toward those goals, to understand better how geography faculty seek and use information resources (both primary and secondary) in their teaching of undergraduate courses. We interviewed nine geography faculty in their offices, during a term in which they were teaching one or more undergraduate courses, asking them a wide range of questions about information seeking for research and teaching, and about how they use information resources in teaching, once acquired. These data were supplemented by interviews with four faculty conducted as part of an earlier ADEPT study, asking questions about the nature of knowledge in geography.

We found that research and teaching are both complementary and competing activities. Information seeking for research and teaching are mostly complementary and mutually reinforcing. Faculty are more likely to encounter useful teaching resources while seeking research resources than vice versa, although the influence goes in both directions. Faculty has extensive requirements for secondary sources and finds the library resources available to be adequate. Their greatest information needs are for research data, maps, and images. The ability to search for primary sources by location and place name also appears to be adequate; their desire is for better searching by concept or theme, both for research and teaching content. The faculty in our study makes extensive use of their own research resources in their teaching.

These findings have a wide range of implications for the functionality and architecture of geographic digital libraries for educational use. Searching by concept is essential, but difficult due to the many ways in which data and images can be interpreted and used. Research on image retrieval in other domains will be needed to address some of these problems. An interim approach would be better browsing capabilities, such as through galleries of thumbnail images. Another implication is the importance of personal digital libraries. Each faculty member interviewed has his or her own approach to 
selecting, collecting, and organizing teaching resources. Thus, each user needs his or her own personal space in which to manage digital objects. Some of the personal digital library content may be selected from a shared space; other content will be imported from personal collections of research and teaching resources. Once gathered, the faculty often wishes to manipulate, annotate, select, and augment resources for their own purposes. To facilitate these practices, ADEPT needs capabilities for importing content from common office software, and for storage of content in standard formats that can be imported and exported to other applications.

A tension exists between ADEPT as a shared collection and as a set of independent, personal collections. Tools can facilitate sharing but cannot overcome barriers such as intellectual property rights and access to proprietary research data. More needs to be known about community practices for sharing teaching and research resources, and this knowledge must inform the dissemination and deployment of digital libraries such as ADEPT.

ADEPT is likely to make the greatest contributions to education by building tools and services that facilitate inquiry learning with primary sources. The geography faculty in our study has the greatest need for primary sources and wishes to make more use of them in their research and their teaching. However, these findings suggest that we must be cautious about constructing a digital library that contains only teaching objects. Information seeking for research and teaching are interdependent, and seeking information for research is more likely to yield teaching resources than vice versa. Thus, we question how much use faculty would make of a digital library that contains solely teaching resources. The capabilities to manage personal collections of research and teaching materials, and to produce lectures and lessons from those resources, appear to offer greater value for this group of geography faculty.

\section{Acknowledgments}

The research reported here is funded by National Science Foundation grant no. IIS-9817432, Terence R. Smith, University of California, Santa Barbara, Principal Investigator (http://www.alexandria.ucsb.edu/) and a subcontract to UCLA, Christine L. Borgman, Principal Investigator (http:// is.gseis.ucla.edu/adept/).

We are grateful to our research subjects, who have given generously of their time throughout the ADEPT project. The gracious cooperation of the Departments of Geography at UCSB and UCLA have made the education and evaluation research on ADEPT possible. Our partners at UCSB have provided thoughtful guidance on all phases of the education and evaluation effort and made use of our results in systems design. Special thanks go to Terence R. Smith, ADEPT PI; Michael Freeston, Project coordinator; and Richard Mayer, Linda Hill, and Tim Tierney for direct involvement in the evaluation efforts throughout this 5-year project. Linda Hill provided valuable comments on an earlier draft of this paper.

\section{References}

Alsos Digital Library for Nuclear Issues. (2004). Retrieved April 3, 2004, from http://alsos.wlu.edu/

Ancona, D., Freeston, M., Smith, T.R., \& Fabrikant, S. (2002). Visual explorations for the Alexandria Digital Earth Prototype. In Visual Interfaces to Digital Libraries: Joint Conference on Digital Libraries (Vol. 2539, pp. 199-216). Portland, OR: Springer-Verlag.

Astin, A.W. (1993). What matters in college? Four critical years revisited. San Francisco: Jossey Bass.

Astin, A.W., \& Chang, M.J. (1995). Colleges that emphasize research and teaching, can you have your cake and eat it too? Change, 27(5), 45-49.

Bates, M.J. (1989). The design of browsing and berrypicking techniques for the online search interface. Online Review, 13(5), 407-424.

Bishop, A.P., Van House, N., \& Buttenfield, B.P. (Eds.) (2003). Digital library use: Social practice in design and evaluation. Cambridge, MA: MIT Press.

Borgman, C.L. (1999). What are digital libraries? Competing visions. Information Processing \& Management, 38(3), 227-243.

Borgman, C.L. (2000a). Digital libraries and the continuum of scholarly communication. Journal of Documentation, 56, 412-430.

Borgman, C.L. (2000b). From Gutenberg to the global information infrastructure: Access to information in the networked world. Cambridge, MA: MIT Press.

Borgman, C.L. (2002). Final report to the National Science Foundation. Paper presented at the Fourth DELOS Workshop. Evaluation of Digital Libraries: Testbeds, Measurements, and Metrics, Budapest, Hungary. Retrieved from http://www.sztaki.hu/conferences/deval/presentations/ final_report.html

Borgman, C.L. (2004, March). The interaction of community and individual practices in the design of a digital library. Paper presented at the International Symposium on Digital Libraries and Knowledge Communities in Networked Information Society, Tsukuba, Ibaraki, Japan.

Borgman, C.L., Bates, M.J., Cloonan, M.V., Efthimiadis, E.N., GillilandSwetland, A.J., Kafai, Y., Leazer, G.L., \& Maddox, A. (1996). Social aspects of digital libraries. Final Report to the National Science Foundation; Computer, Information Science, and Engineering Directorate; Division of Information, Robotics, and Intelligent Systems; Information Technology and Organizations Program. Retrieved from http://is.gseis .ucla.edu/research/dl/index.html

Borgman, C.L., Gilliland-Swetland, A.J., Leazer, G.H., Mayer, R., Gwynn, D., Gazan, R., et al. (2000). Evaluating digital libraries for teaching and learning in undergraduate education: a case study of the Alexandria Digital Earth Prototype (ADEPT). Library Trends, 42(2), 228-250.

Borgman, C.L., \& Larsen, R. (2003). ECDL 2003 Workshop report: Digital library evaluation-Metrics, testbeds and processes. D-Lib Magazine, 9(9). Retrieved from http://www.dlib.org/dlib/september3/09inbrief .html\#BORGMAN

Borgman, C.L., Leazer, G.H., Gilliland-Swetland, A.J., \& Gazan, R. (2001, September). Iterative design and evaluation of a geographic digital library for university students: A case study of the Alexandria Digital Earth Prototype (ADEPT). In P. Constantopoulos \& I.T. Solvberg (Eds.), Research and Advanced Technology for Digital Libraries: 5th European Conference. Lecture Notes in Computer Science (Vol. 2163, pp. 390401). New York: Springer.

Borgman, C.L., Smart, L.J., Millwood, K.A., Finley, J.R., Champeny, L., Gilliland-Swetland, A.G., \& Leazer, G.H. (2004, April). Getting ready for class: The information seeking behavior of geography professors in support of teaching. Paper presented at the Annual Meeting of the American Educational Research Association, San Diego, CA.

Bowker, G.C. (2000a). Biodiversity datadiversity. Social Studies of Science, 30(5), 643-683.

Bowker, G.C. (2000b). Mapping biodiversity. International Journal of Geographical Information Science, 14(8), 739-754.

Boyer Commission on Educating Undergraduates. (2001). Reinventing undergraduate education: Three years after the Boyer Report.: Author.

Case, D.O. (2002). Looking for information: A survey of research on information seeking, needs, and behavior. San Diego: Academic Press. 
Champeny, L., Borgman, C.L., Leazer, G.H., Gilliland-Swetland, A.G., Millwood, K A., D'Avolio, L., et al. (2004). Developing a digital learning environment: An evaluation of design and implementation processes. Paper presented at the Joint Conference on Digital Libraries, Tucson, AZ. Clark, B.R. (1997). The modern integration of research activities with teaching and learning. Journal of Higher Education, 68(3), 242-255.

Coleman, A.S., Smith, T.R., Buchel, O.A., \& Mayer, R.E. (2001). Learning spaces in digital libraries. In P. Constantopoulos \& I.T. Solvberg (Eds.), Research and Advanced Technology for Digital Libraries: 5th European Conference. Lecture Notes in Computer Science (Vol. 2163). New York: Springer.

Dervin, B., \& Nilan, M. (1986). Information needs and uses. Annual Review of Information Science and Technology (ARIST), 21, 3-33.

Dill, D.D. (1999). Academic accountability and university adaptation: The architecture of an academic learning organization. Journal of Higher Education, 38, 127-154.

Egenhofer, M.J., \& Mark, D.M. (1995). Naive geography (No. 95-8). Santa Barbara, CA: National Center for Geographic Information and Analysis.

Foundation, N.S. (n.d.). Digital Libraries Initiative Phase II. Retrieved May 7, 2004, from http://www.dli2.nsf.gov

Gazan, R., Leazer, G.H., Borgman, C.L., Gilliland-Swetland, A.J., Smart, L.J., Ancona, D., et al. (2003). Use scenarios in the development of the Alexandria Digital Earth Prototype (ADEPT). In M.J. Bates (Ed.), Annual Meeting of the American Society for Information Science \& Technology (Vol. 40, pp. 407-415). Long Beach, CA: Information Today.

Gilliland, A.J., Smart, L.J., Millwood, K.A., Finley, J.R., Champeny, L., Borgman, C.L., et al. (in preparation). Pedagogical issues in the design of digital libraries for undergraduate instruction. Manuscript in preparation.

Gilliland-Swetland, A.J., \& Leazer, G.H. (2001). Iscapes: Digital learning environments for the promotion of scientific thinking by undergraduates in geography. In First ACM/IEEE-CS Joint Conference on Digital Libraries (pp. 120-121). New York: ACM.

GIS Dictionary. (1996). Association for Geographic Information and the University of Edinburgh. Retrieved December 15, 2004, from http:// www.geo.ed.ac.uk/agidict/welcome.html

Gottlieb, E.E., \& Keith, B. (1997). The academic research-teaching nexus in eight advanced-industrialized countries. Journal of Higher Education, 34, 397-420.

Hart, R.L. (1998). The relationships betweeen work roles and information gathering of faculty at SUNY, College at Freedonia. Library \& Information Science Research, 20(2), 163-185.

Hay, K., \& Barab, S. (2001). Constructivism in practice. The Journal of the Learning Sciences, 10(3), 281-322.

Hill, L., \& Freeston, M. (2003, June). Introduction to georeferencing in digital libraries, Tutorial. Paper presented at the Joint Conference on Digital Libraries, Houston, TX.

Hill, L., \& Janee, G. (2004). The Alexandria Digital Library Project: Metadata development and use. In D. Hillman \& E. Westbrooks (Eds.), Metadata in practice: A work in progress. Chicago: American Library Association.

Hill, L., Janee, G., Dolin, R., Frew, J., \& Larsgaard, M. (1999). Collection metadata solutions for digital library applications. Journal of the American Society for Information Science, 50(13), 1169-1181.

Hurych, J. (1986). After Bath: Scientists, social scientists, and humanists in the context of online searching. Journal of Academic Librarianship, 12(3), 158-165.

Janee, G., \& Frew, J. (2002). The ADEPT digital library architecture. In Second ACM/IEEE-CS Joint Conference on Digital Libraries (pp. 342 350). New York: ACM

Janee, G., Frew, J., \& Hill, L.L. (2004). Issues in georeferenced digital libraries. D-Lib Magazine, 10(5). Retrieved from http://www.dlib.org

Jenkins, A. (2000). The relationship between teaching and research: Where does geography stand and deliver? Journal of Geography in Higher Education, 24(3), 325-351.

Kuhlthau, C.C. (1988). Developing a model of the library search process: Cognitive and affective aspects. RQ, 28(2), 232-242.

Kuhlthau, C.C. (1991). Inside the search process: Information seeking from the user's perspective. Journal of the American Society for Information Science, 42(5), 361-371.
Lagoze, C. (1997). From static to dynamic surrogates: Resource discovery in the digital age. D-Lib Magazine. Retrieved from http://www.dlib.org/ dlib/june97/06lagoze.html

Larsen, R., \& Wactlar, H. (2004). Knowledge lost in information: Report of the NSF Post-DL Futures Workshop. Retrieved from http://www.sis.pitt .edu/ dlwkshop

Larsgaard, M.L. (1998). Map librarianship: An introduction (3rd ed.). Englewood, CO: Libraries Unlimited.

Larson, R.R. (1995). Geographic information retrieval and spatial browsing. Retrieved from http://sherlock.berkeley.edu/geo_ir/PART1.html

Leazer, G.H., Gilliland-Swetland, A.J., Borgman, C.L., \& Mayer, R.E. (2000). Classroom evaluation of the Alexandria Digital Earth Prototype (ADEPT). In ASIS 2000 Proceedings of the 63rd ASIS Annual Meeting (Vol. 37, pp. 334-340). Medford, NJ: Information Today.

Leckie, G.J., Pettigrew, K.E., \& Sylvain, C. (1996). Modeling the information seeking of professionals: A general model derived from research on engineers, health care professionals, and lawyers. Library Quarterly, 66(2), 161-193.

Lessig, L. (2001). The future of ideas: The fate of the commons in a connected world. New York: Random House.

Manduca, C., McMartin, F., \& Mogk, D. (2001). Pathways to progress: Vision and plans for developing the NSDL: National Science Digital Library. Retrieved December 15, 2004, from http://doclib.comm .nsdlib.org/PathwaysToProgress.pdf

Marchionini, G., \& Crane, G. (1994). Evaluating hypermedia and learning: Methods and results from the Perseus project. ACM Transactions on Information Systems, 12(1), 5-34.

Mark, D.M. (1997). Cognitive perspectives on spatial and spatio-temporal reasoning. In M. Craglia \& H. Couclelis (Eds.), Geographic information research bridging the Atlantic (pp. 308-319). London: Taylor and Francis.

Mayer, R.E., Mautone, P., \& Prothero, W. (2002). Pictorial aids for learning by doing in a multimedia geology simulation game. Journal of Educational Psychology, 94(1), 171-185.

Mayer, R.E., Smith, T.R., Borgman, C.L., \& Smart, L.J. (2002). Digital libraries as instructional aids for knowledge construction. Educational Technology, 42(6), 38-42.

Meadows, A.J. (1998). Communicating research. San Diego: Academic Press.

Monge, P.R., \& Contractor, N.S. (2003). Theories of communication networks. Oxford, UK: Oxford University Press.

Monmonier, M. (1993). Mapping it out: Expository cartography for the humanities and social sciences. Chicago: University of Chicago.

Munby, H., Cunningham, M., \& Lock C. (2000). School science culture: A case study of barriers to developing professional knowledge. Science Education, 84, 193-211.

National Science Foundation, Digital Libraries Initiative, Phase II. (1999). Retrieved December 15, 2004, from http://www/dli2.nsf.gov/

Pettigrew, K.E., Fidel, R., \& Bruce, H. (2001). Conceptual frameworks in information behavior. Annual Review of Information Science and Technology (ARIST), 35, 43-78.

Posner, G., Strike, K., Hewson, P., \& Gertzog, W. (1982). Accommodation of a scientific conception: Toward a theory of conceptual change. Science Education, 66, 221-227.

Reinventing Undergraduate Education: A Blueprint for America's Research Universities. (1998). Boyer Commission on Educating Undergraduates, Carnegie Foundation for the Advancement of Teaching. Retrieved December 15, 2004, from http://naples.cc.sunysb.edu/pres/boyer.nsf/

Reinventing Undergraduate Education: Three Years After the Boyer Report. (2001). Boyer Commission on Educating Undergraduates, Carnegie Foundation for the Advancement of Teaching. Retrieved December 15, 2004, from http://ws.cc.stonybrook.edu/pres/0210066-Boyer_Report_Final.pdf

Reiser, B.J., Tabak, I., Sandoval, W.A., Smith, B.K., Steinmuller, F., \& Leone, A.J. (2001). BGuILE: Strategic and conceptual scaffolds for scientific inquiry in biology classrooms. In S.M. Carver \& D. Klahr (Eds.), Cognition and instruction: Twenty-five years of progress (pp. 263-305). Mahwah, NJ: Erlbaum.

Rogers, E.M. (1995). Diffusion of innovations (4th ed.). New York: Free Press. 
Sandoval, W.A. (1999, December). Epistemic supports for collaborative science inquiry. Paper presented at the Poster presentation at CSCL'99, Computer Supported Collaborative Learning Conference, Palo Alto, CA.

Sandoval, W.A., \& Reiser, B.J. (2003). Explanation-driven inquiry: Integrating conceptual and epistemic supports for science inquiry. Science Education, 87, 1-29.

Serow, R.C. (2000). Research and teaching at a research university. Journal of Higher Education, 40, 449-463.

Smith, T.R., Ancona, D., Buchel, O., Freeston, M., Heller, W., Nottrott, R., et al. (2003). The ADEPT concept-based digital learning environment. In T. Koch \& I.T. Solvberg (Eds.), Research and Advanced Technology for Digital Libraries: 7th European Conference (pp. 300-312). Berlin: Springer.

Star, S.L., Bowker, G.C., \& Neumann, L.J. (2003). Transparency beyond the individual level of scale: Convergence between information artifacts and communities of practice. In A.P. Bishop, N. Van House, \& B.P. Buttenfield (Eds.), Digital library use: Social practice in design and evaluation (pp. 241-270). Cambridge, MA: MIT Press.

Van House, N.A. (2003). Digital libraries and collaborative knowledge construction. In A.P. Bishop, N. Van House, \& B.P. Buttenfield (Eds.), Digital library use: Social practice in design and evaluation (pp. 271296). Cambridge, MA: MIT Press.

Westbrook, L. (1997). Information needs. In A. Kent \& H. Lancour (Eds.), Encyclopedia of library and information science (Vol. 59, Suppl. 22, pp. 316-345). New York: Marcel Dekker.

\section{Appendix A. Faculty Interview}

1. Our DL will contain primary sources. How do you define a primary source in geography?

2. Describe the undergraduate courses you will be teaching next quarter.

a. How many times have you taught that course?

b. How many years have you been teaching at this level?

c. How many students are enrolled? (note: verify against URSA)

d. Does the course have TAs? Do they teach lab sections or just grade for you?

3. Please tell us how you prepare for this course.

e. Where do you do your course preparation?

f. How much time do you spend prior to the start of the quarter?

g. How much time do you spend each week during the quarter?

h. What do you do to get yourself prepared?

i. What tools do you use (software programs, search tools)?

j. What do you do if you're pressed for time?

4. How do you get information and materials to support your teaching?

a. For example, texts, supplemental reading materials, examples, images, maps or other objects you use in class.

b. How do you select problems or questions for weekly assignments and exams?

c. Where do you search? How do you find things?

d. What are your criteria for selecting items?

e. Can you demonstrate now how you would search for something? f. How easy/hard is it to locate new items in support of the course?

g. What features would you like added to tools you already use?

5. What do you do with the materials you've gathered prior to introducing them in the classroom?

a. Do you need to modify items? How do you do it (i.e., what tools? what needs to be changed?)?

b. Where do you "store" your materials?

c. How do you arrange them for yourself?

d. Do you retain them for further use?

6. If we were to build the perfect system to help you locate resources in support of your teaching, what would you like the system to contain?

a. How would you search it?

b. What features should it have?

c. What role would your TAs play in using that system?

7. How does your information seeking for your own research compare to your information seeking for instruction?

a. Do you use the same sources? In the same ways?

b. Describe your current research project and give an example of when you needed to find information for it.

c. How much information is primary? How much is secondary?

\section{Appendix B. Applications to Learning Situations and Evaluations of ADEPT Faculty}

\section{Pre-ADEPT Classroom Implementation Interview}

1. What is Geography?

2. How is knowledge about Geography produced?

3. How do you think Geography should be taught?

4. Why is studying Geography important?

5. What are your goals as a teacher of Geography?

6. What is most important to teach about the discipline of Geography?

7. What are your specific goals as a teacher in this course?

8. How would you characterize your pedagogical approach in this course?

9. What is most important for undergraduates as compared to graduates and other types of students to learn about Geography?

10. What is your previous experience with information technology?

11. How would you define geospatial information technologies?

12. Where do you see the value of geospatial information technologies for your students' learning?

13. Where do you see the value of geospatial information technologies for you as a teacher?

14. What do you expect from implementation of ADEPT in the classroom?

15. Are there any obstacles you foresee in using ADEPT in the classroom? 


\section{Appendix C. Categories Coded in Interviews}

\section{Concept}

Desiderata

Student Evaluation

Information Services

Information Sources

Information Use

Constraint

Influence

Information Searching Behavior

\section{Selection Criteria}

Information Tools

Instructional Preparation Tasks

Instructional Preparation Time

Instructional Theme

Pedagogy Goal

Presentation Format

Primary Source

Research Work

Scientific Questions

Teaching Experience
An idea an instructor wishes to convey during instruction. Essentially it's a topic, or subject of instruction that can be thought of as a vocabulary term. This can include any of the topics that are taught in the particular instructor's course. Topics may vary depending on the course and instructor.

Desired digital library tools, services, or content. Something a faculty member would like to have in an ideal digital library. This can include digital references, digital images (video and still), ability to modify images, ability to print, able to access tools from one place.

The judgment or assessment of student performance and/or learning outcomes. This includes the ways that a professor assesses students, it can include what their exams are focused on (definition of terms, major points covered in class, history of the field) or any other measurement that is used (i.e. labs, class participation).

Human mediated assistance in using information. For example, interlibrary loan has humans overseeing citation verification and document delivery. This includes the use of interlibrary loan, cartographers, or other services that are relevant.

The point or place from which information originates. Real actual content. This is coded when the instructor says where they get information. This includes colleagues, books, web, journals, library, organizations, etc.

Faculty behavior, actions, or conduct while using information sources, tools, or services.

Subcategory of Information Use. Any restriction on information use in support of instruction. A barrier to access, searching, or use. Includes limitations on time, limitations of money, lack of suitable information content, inappropriate tools, organizational practices (ex., nobody in our dept does that), available equipment in classroom, etc.

Subcategory of Information Use. Any person or thing having an effect, power, or sway over information use in support of instruction. This can be coded if the tenure process is mentioned as an influence, or amount of credit given for instructional innovations, etc.

Broad subcategory of Information Use. The actions and conduct of faculty member while in pursuit of information. Includes the individual's recognition of a knowledge gap or anomalous state of knowledge that instigates the pursuit or seeking of information and any behaviors they exhibit during the search process, including reading to find out new or current information on a topic. Can be broken down into active and passive searching behaviors. For example, active searching would be typing keywords into a search engine. Passive searching would be serendipitous squirreling away of any information deemed useful while in the process of doing something else (ex., walking to work, notice a flyer on weather, \& grab a copy to share with the class).

Subcategory of Information Use. The factors by which a faculty chooses an information source or tool.

An implement or instrument that assists information use. It is something that helps you to get a task done. Automated (i.e., it's software) rather than human based. Examples, search engine, library catalog, word processing software, photocopier, overheads.

Actions faculty take in advance of instructional presentation in order to get themselves ready or suited to the activity. This may include reading (in order to refresh memory on topics-see reading under Information Searching Behavior), gathering more images to illustrate a concept, revising notes, etc.

Period spent performing instructional preparation tasks. This will be a specified length of time that it takes to prepare, like a week, day, hour, 20 minutes, etc.

How the faculty member groups or organizes concepts for presentation or for learning. This can refer to the organization of the material for class and/or how materials in class are organized for presentation. An example of this is when a teacher says that they organize their material by week by course, or any other type of organization system referring to instruction (i.e., by topic).

An aim or object towards which the practice of teaching is directed. The faculty members' principles of instruction. This is what the teacher wants the students to learn; it may include specific topics, or definitions.

The means or vehicle by which an instructor imparts information to students. Examples include: PowerPoint presentations, and chalk drawings on board.

Faculty definition of what constitutes a primary source of information. This may include referring to a primary source as an image, up to date information, data collected by a researcher, etc.

Tasks done in pursuance of research.

Queries of uncertainty or doubt, phrased in formal thesis/hypothesis, or in a manner that will structure the formal pursuance of answers.

The length of time that a faculty member has taught undergraduate courses, and the length of time teaching a given course or subject. This will be a number or approximate length of time, many years, ever since I can remember, 4 years, 20 years, etc. 